\title{
Liquid biopsy - emergence of a new era in personalized cancer care
}

\author{
Jessy Abraham ${ }^{1^{*}} \mathbb{D}$, Sunita Singh ${ }^{2}$ and Shalaka Joshi ${ }^{3}$
}

\begin{abstract}
The most successful treatment for cancer involves identifying druggable, biological markers for targeted therapy. In the clinical setting, surgical removal of tumors is the only procedure for identifying such targetable molecules. Shed from tumor cells, these markers are also present in circulating blood, albeit in very negligible amounts. Liquid biopsy is a procedure performed on a blood sample to look for such circulating cancer markers cells or pieces of nucleic acid from the tumor. The procedure shows promise in revolutionizing personalized cancer treatments. Here we briefly review the technique, characterization, and its utilization in clinics.
\end{abstract}

Keywords: Liquid biopsy, Circulating tumor cells, Cell free DNA, Cell free RNA, Clinical utility

\section{Background}

Today, cancer remains the leading cause of premature deaths worldwide. Treatment relies on profiling a piece of biopsied tumor tissue. However, the ease of acquiring biopsy depends on patient condition and tumor accessibility. In the case of advanced or metastatic non-small cell lung cancers (NSCLC) as many as $31 \%$ of cases do not have accessible tissue [1]. Likewise, majority of patients with pancreatic cancer progress to either locally advanced or metastatic disease in the asymptomatic phase and as many as $80 \%$ presents late with metastasis at diagnosis [2]. Progress remains hindered also by diverse landscape of tumor and technical limitations involved in sampling of biopsied tissue. Following excision, biopsy samples are fixed and sections, similar to a bread loaf, are cut and the tddop most layers are sliced again for pathological staining. But tumors are characterized by intra-tumor heterogeneity arising from clonal evolution of individual tumor cells (Fig. 1) [3]. So, the technique may fail in capturing newly evolving, genetically distinct cells that do not lie on the surface of the bread-loaf section (Fig. 2). Similarly, primary tissue from pancreatic ductal adenocarcinoma patients is usually available only by fine-needle aspiration biopsies and there is a high chance of missing aggressive clones [4]. Besides, a standard protocol in cancer

\footnotetext{
* Correspondence: jessyabraham@outlook.com

'Department of Biochemistry, All India Institute of Medical Sciences, Raipur, Chhattisgarh 492099, India

Full list of author information is available at the end of the article
}

management involves periodic monitoring for progression and/or recurrence of the cancer. Because a tissue biopsy can be painful and expensive, most patients shy away from a repeat biopsy. And in most cases the physician does not know where to look for metastasis. Even, commonly used imaging techniques like ultrasonography, positron emission tomography (PET), computed tomography (CT) and magnetic resonance imaging (MRI) [5] cannot detect many early-stage cancers and very small metastases [6]. While challenges in obtaining adequate tumor tissue and issues of heterogeneity continue to hamper tissue profiling, minimally invasive technologies to capture genomic contents of tumor in various bodily fluids like blood, urine, saliva, sweat and tears combined with sensitive genotyping assays, have become available. "Liquid biopsy" is the term coined to describe such diagnostic procedures performed on cancer-derived material captured in a blood sample.

Since, cancer cells that detach from solid tumors circulate in the peripheral blood, analyzing blood of patients with cancer holds the possibility for capture and molecular analysis of diverse tumor-derived materials. In normal, healthy individuals, cellular debris from apoptotic or necrotic cells is normally phagocytized by infiltrating macrophages and cleared from the circulation. However, this clearance mechanism does not proceed effectively in cells derived from tumor mass, leading to an accumulation of cellular debris including DNA, and its release into the circulation [7]. By and large, cellular components sampled 


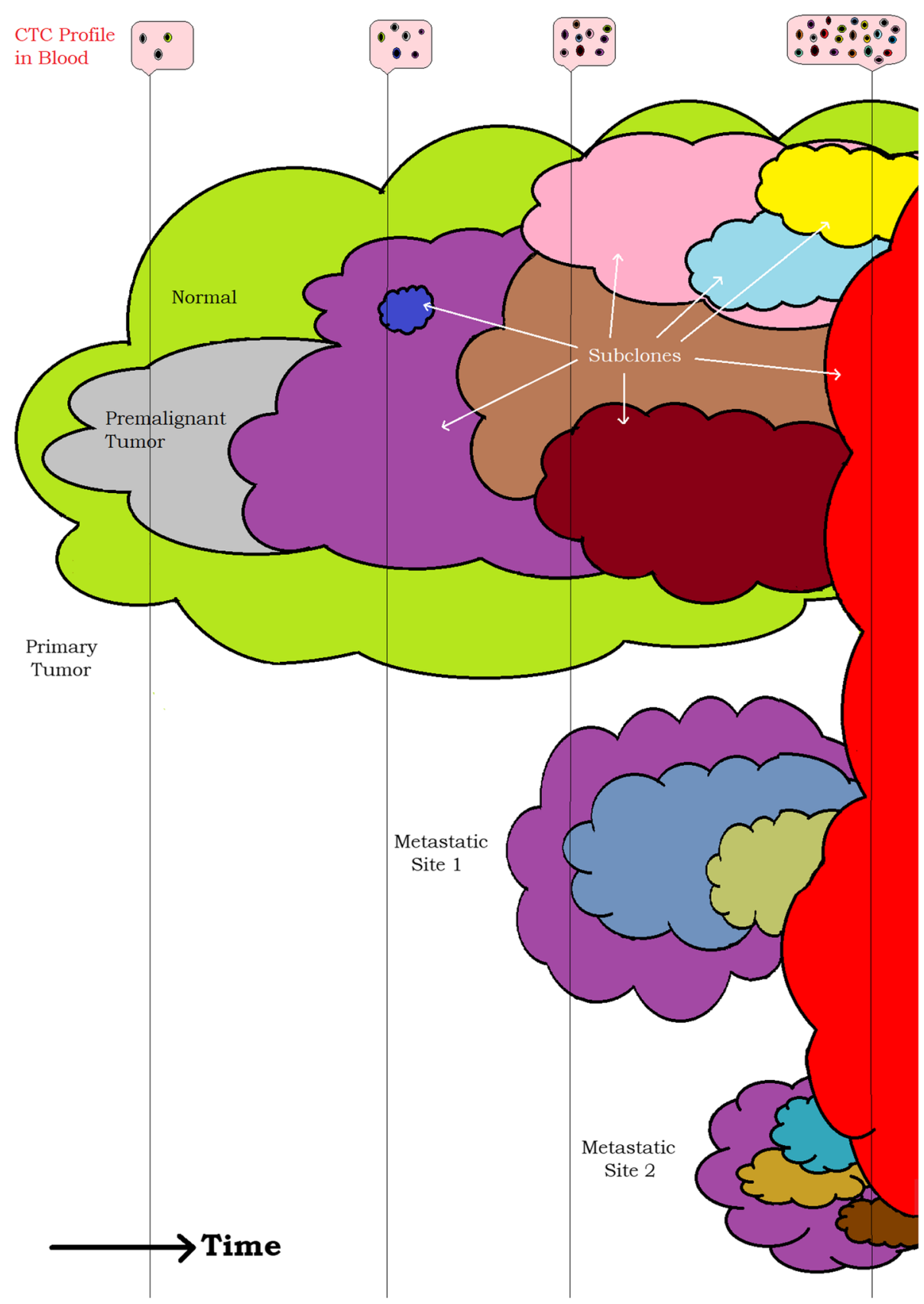

Fig. 1 Snapshot of the evolving tumor landscape. Tumor cells undergo frequent mutations resulting in emergence of distinct sub clones. This leads to ever evolving/ changing landscape of tumor cells which are difficult to monitor by traditional standard biopsy. But with recent advances in single cell detection technologies, it has become possible to capture and characterize cells shed from these distinct sub clones into the blood. They are shed either by dying tumor cells or are tumor cells that have detached from parent primary tumor and have metastatic abilities

from the blood of cancer patients is highly consistent with gene alteration patterns reported in traditional tumor tissue testing (https://www.cancer.gov/news-events/cancercurrents-blog/2016/asco-liquid-biopsy) [8, 9], which makes these circulating cancer-derived materials in the bloodstream an appealing alternative to overcoming some of the challenges described above. Because blood collection is simple and minimally invasive, this alternative method is currently being developed by many investigators, particularly with the aim of obtaining a complementary tool to tumor biopsy to predict what drugs will work for a patient and monitor how a tumor changes over time. Herein, we provide a brief overview of the various types of tumorderived material that can be sampled using liquid biopsies. Subsequently, we discuss the available technologies for extraction of molecular information from liquid biopsy 


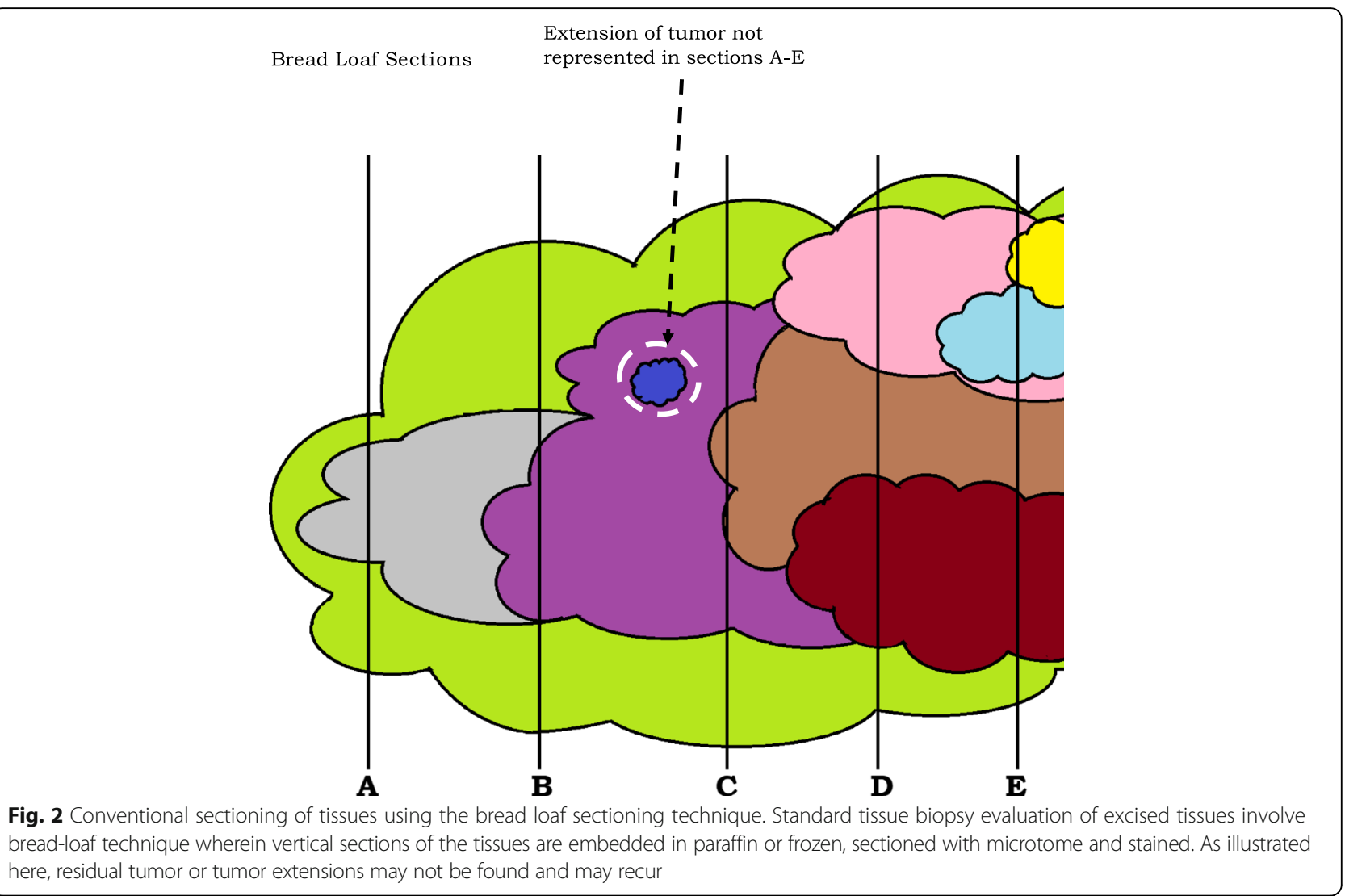

samples and their clinical use, focusing mostly on those associated to DNA derived from blood samples.

\section{Approaches to liquid biopsy}

Cancer at any stage can shed tumor cells as well as fragments of cancer-causing DNA into the blood system and may give good indication of mutations in the tumor at the time of sampling. The more advanced the cancer, the more likely tumor cells and cancer-causing DNA can be found in the blood. Liquid biopsy techniques detect different blood-based biomarkers including circulating tumor cells (CTCs), circulating tumor DNA (ctDNA), also known as cell free DNA (cfDNA), circulating RNA (cfRNA), and exosomes.

\section{Circulating Tumor Cells (CTCs)}

CTCs represent intact, viable non-hematological cells with malignant features that can be isolated from blood [10]. As early as 1869, Ashworth described CTCs in cancer patients [11] and its presence in blood stream was demonstrated by Engell in 1955 [12]. However, interest in CTCs increased when high CTC counts in blood samples from patients with metastatic breast cancer correlated with poor prognosis and therefore showed prognostic potential. CTCs are released into the bloodstream during metastatic spread of the cancer through blood and are present as single cells or clusters [13]. They have been detected in various metastatic carcinomas including lung [14], breast [15, 16], prostate [17], and colorectal cancer [18] but are extremely rare in healthy subjects and patients with nonmalignant diseases [19]. Even in patients with metastatic cancer, they occur on average at a frequency of 1 in 100 million cells and are mixed with approximately 10 million leukocytes and 5 billion erythrocytes per $1 \mathrm{ml}$ blood [20]. And, due to apoptosis of CTCs, which begins soon after separation from the tumor of origin, they are extremely fragile [21]. Next generation sequencing (NGS) has revealed CTCs carry mutation signatures that resemble the signatures of their primary tumors including driver and druggable mutations like $A P C, K R A S, T P 53, E R B B 3, F B X W 7$ and ERBB2 [22].

\section{Cell free DNA (cfDNA)}

Circulating cell-free DNA (cfDNA) are small DNA fragments found circulating in plasma or serum, as well as other bodily fluids. The presence of cfDNA in blood plasma was discovered in 1948 by Mandel and Metais [23]. But it was only recently shown that molecular profile of cfDNA is similar to tumor tissue DNA. A major breakthrough came with the advancement of NGS technologies for mutation detections which allowed for the 
sequencing of DNA and RNA much more quickly and cheaply than the previously used Sanger sequencing. Many clinical trials are intensively investigating correlation of mutations in cfDNA to disease progression especially for hard to access cancers such as NSCLC and pancreatic cancer [24]. Patients with distant metastases have a significantly higher level of cfDNA compared to patients without metastases. Total mutation-specific cfDNA decreases during treatment but the levels increase later on in patients with recurrence $[25,26]$.

Plasma cfDNA usually are fragments of about $~ 170$ $500 \mathrm{bp}$, thought to originate mostly from apoptotic cells [27]. Initial studies, such as those performed by Diaz et al., suggest that when both cfDNA and CTCs are present, cfDNA fragments outnumbered CTCs by 50 to 1 [28]. In addition, a direct comparison of mutation detection on cfDNA vs CTCs showed a higher abundance of the mutation on the cfDNA from the same patient [29]. An advantage of cfDNA is that they are relatively stable and can be analyzed from bio-banked biofluids, such as frozen plasma. The most commonly used vacutainers for blood collection for isolation of cfDNA are proprietary Streck Cell-Free DNA BCT $^{\circ}$ and CellSave tubes and standard K2EDTA tubes. Studies comparing the optimal conditions for blood collection and storage temperature for cfDNA have found similar abundance and stability for up to $6 \mathrm{~h}$ in all tube types with no effect on the yield $[30,31]$.

\section{Exosomes and circulating RNA}

Tumor cells actively release several species of cfRNAs, into the blood including non-coding RNAs (e.g., microRNAs or miRNA, small nucleolar RNAs, PIWIinteracting RNAs, and long non-coding RNAs). Such species are enriched in exosomes and strongly resist RNases. High levels of exosomes are found in several bodily fluids from cancer patients [32] and because of their resistant nature, exosomes and miRNA can be isolated from biofluid samples and stored for many years in the freezer [33]. Their composition seems to reflect that of the parental cells and therefore provide a novel type of biomarker for various patient scenarios [34]. Like cfDNA, circulating miRNA seems to give a better picture of variations present in the tumor than CTC [35]. In the last few years, different alterations have been described inside the exosomes derived from NSCLC cells mirroring the processes inside tumor cells, such as EGFR mutation, translocations, or miRNA deregulation [36].

Recent studies have shown that plasma miRNA levels significantly correlate with larger tumor size, chemoresistance, and recurrence of tumors [37]. miRNA-144-3p and miR-210 are significantly up-regulated in plasma and tissues from clear cell renal cell carcinoma compared to healthy control plasmas or urine samples [38, 39]. A study of plasma miR-224 levels in patients with hepatocellular carcinoma found that plasma levels could accurately predict presence of small tumors which were less than $18 \mathrm{~mm}$ preoperatively [37]. Similarly, the overexpression of miR-21 and its detection in plasma contributed to chemo-resistance in esophageal squamous cell carcinoma [40].

Not all miRNA is upregulated in cancer, however. Fan and coworkers found five serum miRNAs (miR-16-5p, miR-17b-5p, miR-19-3p, miR-20a-5p, and miR-92-3p) that were significantly downregulated while miR-15b-5p was significantly upregulated in NSCLC [41]. Treatment procedures also affect the levels of circulating miRNA. After chemotherapy, levels of miR-199b-5p, miR-301b, miR-326, miR-361-5p, miR-625 and miR-655 reduced in plasma from patients with acute myeloid leukemia though they were abundant at diagnosis [42]. Similarly, plasma miR-375 could differentiate between patients with prostate cancer and benign prostatic hyperplasia [43].

\section{Extraction of molecular information}

The first step in attaining valuable information pertaining to cancer treatment is efficient isolation and specific recovery of the circulating CTC, cfDNA and cfRNA shed by the tumor cells while leaving behind those molecules shed by normal cells. Since very few CTC, cfDNA, exosomes and cfRNA are circulating in the blood, the initial step involves enrichment or purification of these tumor released materials from other blood components in order to increase sensitivity and specificity. They have been purified on the basis of physical properties, including size, density, and electric charges. CTCs can also be positively or negatively enriched on the basis of the expression of cell surface antibodies like EpCAM. Most authors use QIAamp Circulating Nucleic Acid (Qiagen) which utilizes magnetic bead based technology to isolate plasma tumor derived DNA. A comparison of three popular kits by authors Pérez-Barrios and group found no significant differences in recovery of cfDNA extracted using kit from Qiagen or Maxwell ${ }^{\circ}$ RSC ccfDNA Plasma Kit (Promega) but the cfDNA yield from MagNA Pure Compact Nucleic Acid Isolation Kit I (Roche) was significantly less [44]. But others have found that the yield of cfDNA using the traditional phenol/chloroform/ethanol method in the presence of glycogen was better than that isolated in the absence of glycogen or by commercially available kit [45]. After isolation, subsequent analysis includes fluorescence in-situ hybridization (FISH), microarray, immunofluorescence, sequencing, flow cytometry and RT-PCR. Digital PCR comprising of droplet-based systems (ddPCR), microfluidic platforms for parallel PCR, NGS, BEAMing (Beads, Emulsions, 
Amplification and Magnetics) and amplificationrefractory mutation system (Scorpion-ARMS) assay are additional techniques that can detect rare circulating tumor DNA sequences without the need for reference standard or standard curves.

Current approaches for detection of liquid biopsy components from blood can be divided into three different categories: methods targeting specific druggable driver mutations or all possible aberrations in cfDNA, methods to isolate and identify CTCs, and methods to isolate and identify exosomes, which are discussed in detail below.

\section{Methods targeting druggable mutation and other aberrations in cfDNA}

Majority studies report screening for mutations that have been already validated in cancer tissue biopsy and compare the concordance of patient-matched plasma and tumor tissue samples. Over expression of mutated epidermal growth factor receptor (EGFR or ErbB1 or $H E R 1$ ) is one such major marker seen both in tissue biopsy and cfDNA. The two most common mutations are exon 19 deletions (Del19) and L858R missense substitutions resulting in constitutive activation of the receptor without ligand binding. Presence of these mutations are strong predictors of efficacy for tyrosine kinase inhibitors (TKI) such as Gefitinib, Afatinib, and Erlotinib, or $\mathrm{mAb}$ such as Cetuximab. Therefore, these mutations on EGFR are also known as TKI- sensitive mutations [46]. A point mutation that substitutes methionine for threonine at amino acid position $790(\mathrm{~T} 790 \mathrm{M})$ produces majority of TKI acquired resistant cases for first generation EGFR inhibitors and is known as TKI- resistant mutation [47]. For detection of EGFR mutations, maximum authors use commercially available primer and probes and amplification by real time PCR. However, there have been instances of misdiagnosis of mutations in EGFR by routine EGFR mutation tests [4, 48].

Wu et al. [49], recently published a paper on evaluating the feasibility of detecting EGFR mutations in lung adenocarcinoma. Using the Therascreen EGFR 29 kit (Qiagen), they tested cfDNA purified from either $3.0 \mathrm{ml}$ serum or $4.0 \mathrm{ml}$ plasma to detect 29 somatic mutations in the EGFR by real time PCR. They found higher mutation detection rates in plasma than in serum $(60.5 \%$ and $28.6 \%$ respectively). Patients who were cfDNA+ for EGFR mutations exhibited characteristics associated with more advanced disease compared with cfDNA- patients. Afatinib significantly improved progression free survival vs chemotherapy in patients with common EGFR mutations, the effective benefit being more pronounced in patients with Del19 vs L858R mutation-positive tumors (8.3-9.7 months vs $3.3-4.6$ months; $P=0.0009$ ). Karachaliou and colleagues [50] found serum EGFR L858R mutation correlated with overall survival, progressionfree survival, and response to Erlotinib therapy in a cohort of NSCLC patients enrolled in EURTAC trial. For their screening, they used an in-house developed peptide nucleic acid mediated 5'-nuclease real-time PCR. Yu et al., developed a multiplex picoliter-droplet digital PCR for quantitative assessment of EGFR mutations in cfDNA derived from advanced NSCLC patients. They found fluctuations in EGFR mutant abundance in serial plasma cfDNA (collected over 2 months) correlating with the changes in tumor size as assessed by imaging scans [51].

Mok and colleagues [25] extracted cfDNA from blood and used allele-specific Cobas 4800 PCR assays from Roche Molecular Systems Inc. to detect EGFR mutations in NSCLC patients. The study cohorts included patients randomized to receive platinum-based chemotherapy plus sequential Erlotinib or placebo. The authors considered samples showing at least one activating mutation (Del19, L858R, G719x, or L861Q) to be positive for EGFR mutations. Patients with EGFR mutation-specific cfDNA and treated with Erlotinib presented a significantly better outcome than patients treated with placebo [progression-free survival-13.1 vs 6.0 months; $P<0.0001$ ], while no difference emerged between those who were negative for $E G F R$ mutation-specific cfDNA and treated with Erlotinib or placebo [progression-free survival-6.2 vs 6.1 months]. The ASSESS trial in Europe and Japan (NCT01785888, designed for real-world diagnostic validation of Therascreen EGFR PCR Kit (Qiagen), cobas EGFR Mutation Test (Roche), Cycleave (Takara Bio Inc., Kusatsu, Japan) and PNA-LNA PCR Clamp kits (Qiagen), for testing EGFR mutation found identical sensitivity when both plasma and tissue was tested using the same commercial kit [52]. Phase I expansion component of the AURA Phase I/II study (NCT01802632) conducted in USA and Japan, also, validated the use of various EGFR testing methodologies including cobas $^{\bullet}$ EGFR Mutation Test, Sanger sequencing, Therascreen ${ }^{\circ}$, PNAClamp ${ }^{\text {Tw4 }}$, and Sequenom MassARRAY $^{\oplus}$ [53].

TKI-sensitive and TKI-resistant mutations are not the only mutations detected in blood cfDNA. Seki et al. [54], did find TKI-sensitive (L858R and Del 19) mutations in patients with lung adenocarcinoma who received TKI therapy but developed resistance. And, only half of resistant patients harbored TKI-resistant (i.e., T790 M) mutations in cfDNA and tissues. Instead, L747P substitution mutation was found in a patient who was TKIresistant, harbored TKI-sensitive mutant DNAs and did not have the TKI-resistant - T790 M mutation. L747 participates in a key hydrophobic core that stabilizes the inactive form of EGFR. Therefore, leucine to proline substitution would disfavor the formation of this hydrophobic core, thereby leading to constitutive activation of 
the mutant EGFR [55] and could explain resistance to EGFR inhibitor. Chabon and colleagues [56] performed CAPP-Seq cfDNA analysis from 2 to $4 \mathrm{ml}$ of plasma to identify mechanisms responsible for resistance to a third-generation EGFR inhibitor, rociletinib, in NSCLC patients. They found a novel L798I mutation which directly lies adjacent to the covalent binding site of rociletinib in EGFR, thereby preventing rociletinib binding and resulting resistance.

Non responders to anti-EGFR therapy is also seen in individuals with somatic mutations in the KRAS protooncogene. Majority cases present various single point mutations at codon 12. Biorad has a commercial kit comprising of ddPCR amplification using the QX200 ${ }^{\mathrm{mm}}$ Droplet Digital $^{\mathrm{Tm}}$ PCR System and the PrimePCRTM KRAS Mutant Probe assays to detect G12D, G12R and G12 V mutations in KRAS. These are the most frequent KRAS mutations found in sporadic pancreatic ductal adenocarcinoma primary tumors. The specificity for detection of G12D and G12R is $100 \%$. However, there are reports of non-specific amplification of G12D mutant DNA with the G12 V assay. The system is quite sensitive for the detection of mutant DNA as about 0.5 ng corresponding to 37 copies can be detected by this technique. Pancreatic cancer patients that tested positive for any of the KRAS mutation in plasma cfDNA, using the Biorad system, had a significantly shorter overall survival than patients who tested negative for a mutation (60 days vs 772 days respectively) [4].

Nygaard and group [26] used in-house designed primers and $\mathrm{qPCR}$ to detect six mutations of codon 12 and one in codon 13 of the KRAS gene in patients with newly diagnosed, histopathologically confirmed stage IIIIV NSCLC and at follow up following chemotherapy alone or in combination with bevacizumab. Only $10 \%$ (7/69) of patients were identified with a plasma KRAS mutation before start of treatment which persisted during the treatment course. But in two patients there was no mutation at the start of treatment, but mutation was detected at progression. In another study, analysis of metastases from colorectal cancer patients who developed resistance to cetuximab or panitumumab showed the emergence of KRAS amplification in one sample and acquisition of secondary KRAS mutations in 60\% (6/10) of the cases [57]. Comparable results were found in a prospective study of patients with metastatic colorectal cancer during treatment with third line anti-EGFR therapy, cetuximab and irinotecan. Plasma KRAS status, unlike that in tumor tissue, was a strong predictive and prognostic factor for response to these third line antiEGFR therapy $[58,59]$.

Others have tried a technique referred to as enriched polymerase chain reaction followed by restriction fragment length polymorphism (PCR-RFLP) to distinguish between wild type and mutant allele. In this technique a mismatched primer is used for PCR, which introduces restriction site and can be used to differentiate the wild type allele from mutant allele. The technique has been tested in differentiating early colorectal lesions based on the presence of mutant KRAS status in cfDNA and was found to have significant predictive capability [60-62].

Generally, KRAS mutations occur in a mutually exclusive manner along with $B R A F$ mutations. Together mutations on these genes lead to the constitutive activation of EGFR signaling through the oncogenic Ras/Raf/Mek/ Erk pathway. The most common mutation in BRAF is V600E substitution and individuals with the BRAF mutation benefit from targeted inhibition of BRAF protein with BRAF inhibitors [63]. Janku and group analyzed $B R A F$ mutations in cfDNA using the Idylla BRAF Mutation Test (Biocartis) - a real-time PCR-based system. BRAF V600E mutation was detected in $29 \%$ plasma cfDNA samples from patients with diverse advanced cancers. There was $88 \%$ agreement with mutations in tissues and sensitivity of $73 \%$ and specificity of $98 \%$. A higher percentage of mutant BRAF (V600E) corresponded with shorter overall survival (10.7 months vs 4.4 months respectively) and shorter time to treatment failure in patients receiving BRAF/MEK inhibitors. Idylla assay showed 100\% concordance with those of ddPCR QX200 (Bio-Rad) and BEAMing (SysmexInostics) [64]. A significant decrease in plasma BRAF V600E concentrations was found in patients with melanoma being treated with BRAF inhibitors, dabrafenib or vemurafenib and at the moment of best response but at progression, there was a significant increase in the concentration of plasma BRAF V600E [65]. Vemurafenib and dabrafenib are selective inhibitors of activated $B R A F$ V600E, and tumor tissues positive for BRAF V600E by Cobas 4800 BRAF V600 Mutation Test (Roche Molecular Systems, Inc.) (https://www.cancer.gov/about-cancer/treatment/ drugs/fda-vemurafenib), are approved by the US FDA and the European Medicines Agency (EMA) for the treatment of unresectable or metastatic melanoma.

Clinical need for KRAS mutation testing is largely related to the use of anti-EGFR antibody therapy. Therascreen ARMS assay (Qiagen), Competitive Allele-Specific TaqMan PCR (castPCR, Life Technologies), and Invader Plus assay with peptide nucleic acid clamping (InvClamp assay (Hologic, Inc. Marlborough, MA, USA) are widely used in both clinical and trial settings to determine equivalence for KRAS mutation. castPCR plate includes primer and probes for additional KRAS mutations and BRAF V600E, which are not included in Therascreen or Invader Plus [66]. There is US FDA approval of the Therascreen KRAS RGQ PCR Kit (Qiagen) and the Cobas ${ }^{\circ}$ KRAS Mutation Test (Roche Molecular Systems, Inc.) for detecting druggable mutations in 
formalin-fixed paraffin-embedded (FFPE) tissues of specific cancers. Routine KRAS/BRAF screening is performed before initiating anti-EGFR therapy in patients with colorectal cancers to predict non-responsiveness to anti-EGFR therapy and to prevent drug-induced toxicity thereby avoiding heavy expenses related to the treatment [67]. Tabernero et al., investigated the use of cfDNA and plasma protein biomarkers to predict the clinical utility of regorafenib and assess prognosis in patients with metastatic colorectal cancer enrolled in CORRECT trial. They used BEAMing technology to identify KRAS, $P I K 3 C A$, and BRAF mutations in DNA obtained from plasma and FFPE tissue specimens. Patient-matched fresh plasma and FFPE tumor samples showed concordant mutation status in $76 \%$ of patients for KRAS, $88 \%$ patients for PIK3CA, and $97 \%$ of 236 patients for $B R A F$. Correlative analyses showed a trend for regorafenib clinical benefit across patient subgroups defined by KRAS and PIK3CA mutational status. Most of the discordance in KRAS status were due to the detection of a mutation in plasma but not in the patient-matched FFPE tumor sample [68]. As represented in Figs. 1 and 2, technical limitations prevent complete identification of all cells within a tumor mass and could be one of the reasons for discordance in KRAS status between ctDNA and FFPE analysis.

Since both FFPE and cfDNA samples are fragmented and found in limited quantities, technologies for analyzing FFPE DNA has been exploited for use with cfDNA [69]. When tested using identical platforms, some studies report good agreement in the mutation status between cfDNA and FFPE [44, 70]. Higgins et al., found $100 \%$ concordance of PIK3CA mutation status by BEAMing between FFPE samples and corresponding cfDNA from blood [71]. Similarly, Janku and colleagues found concordance in $91 \%$ cases for BRAF mutations, 99\% cases for EGFR mutations, $83 \%$ cases for KRAS mutations and $91 \%$ cases for PIK3CA mutations in FFPE and cfDNA in 157 patients with advanced cancers [72]. Using Scorpion ARMS method, Duan and colleagues found an overall concordance of EGFR mutation status between plasma and tissue samples to be $80 \%$ [73]. But, others have found poor concordance between FFPE and cfDNA from blood. Adamo and colleagues did not detect any mutations in the cfDNA though tumors tissues had a KRAS G12D mutation [74]. Similarly, Grasselli and colleagues also saw very high heterogeneity and poor correlation in the mutational load between tissueplasma results [75]. These differences could potentially explained by low tumor burden [75] or ctDNA shedding or low total number of tumor cells in the primary tumor [76] or due to differences in protocol for isolating DNA from FFPE and plasma [44]. Also, formalin fixation introduces DNA denaturation, and introduction of non- reproducible sequence alterations in DNA [77]. Unlike cfDNA, there are also issues in identifying amplicons displaying high GC content in FFPE DNA [78].

In addition to the druggable mutations, there are studies showing the presence of mutations or modifications in other genes, though the clinical significance of these novel alterations needs to be determined. Most of these changes have been identified by comparing the plasma samples of specific cancers with that of healthy volunteers. Some examples include the alterations in estrogen receptor 1 and erb-b2 receptor tyrosine kinase 2 $(E R B B 2)$ of breast cancer patients which were not seen in tissues, but have been detected in cfDNA [79-81]. Uehiro and colleagues [82] compared the methylation signatures of nearly 140 candidate genes in plasma samples to detect early breast cancer in patients. Using the Illumina Infinium Human Methylation 450 BeadChip Assay platform, they identified methylation in 12 genes that were present both in peripheral blood mononuclear cells and primary tumor tissues from breast cancer patients, but not in peripheral blood mononuclear cells from healthy volunteers. They developed an algorithm by incorporating their results and were able to predict early breast cancer with fairly high sensitivity (86\%) and specificity (82\%), making the model comparable to mammography screening. This is exciting because more women are being diagnosed with higher stage cancer at a younger age and the accuracy of mammography is not reliable due to high breast density in young women.

Unlike, PCR-based methods which detect only known mutations using specific primers and probes, NGS look at entire genes which allow to identify rare and novel mutations driving cancer in a single run [83]. But due to low concentration of cfDNA, complexity of analysis and interpretation, and economics involved in NGS, targeted amplicon-based NGS platforms are also being developed [84]. In targeted NGS panels, areas of genes that are most often mutated in cancer are targeted and enriched using multiplex-PCR based library preparation [85]. Illumina has released TruSight Tumor 15 which assesses 15 genes that are frequently mutated in solid tumors. Though, it has been optimized to work with highly fragmented and degraded FFPE DNA, recent studies have shown that it can be used to analyze mutations in cfDNA (https://www.illumina.com/). The Ion Ampliseq Colon and Lung cancer panel on the Ion Torrent Personal Genome Machine selectively amplifies 90 amplicons that encompass 1825 mutational hotspots of 22 genes related to colon and lung cancer [86-88]. It has been clinically validated in a retrospective study of 39 NSCLC samples and 51 colorectal cancer samples [84]. The ctDx ${ }^{\mathrm{Tu}}$ Resolution Bio ctDx Lung assay (Resonance Bioscience) is another commercially targeted NGS system for detecting driver mutations targeted by 
specific FDA-approved therapy or therapies now in clinical trials [89] (http://www.resolutionbio.com/assays/ nsclc.html). The sensitivity and accuracy of these targeted NGS platform are 100\% for detecting variants of driver genes at an allelic frequency $>4 \%[79,84,90]$. Malapelle and colleagues [91] has designed and tested a "SiRe" panel to identify 568 clinically relevant mutations in six genes (EGFR, KRAS, NRAS, BRAF, cKIT and $P D G F R \alpha$ ) involved in NSCLC, gastro-intestinal stromal tumor, metastatic colorectal carcinoma and melanoma. In the prospective studies, SiRe panel was able to detect the emergence of the EGFR T790 M mutation in 42.9\% of patients at tumor progression after TKI treatment. Thermo Fisher has also recently launched a commercial NGS-based assay, Oncomine Comprehensive Assay v3, to detect relevant alterations in several critical receptor kinases, DNA repair pathway and cell cycle pathway genes in both blood and FFPE tissue samples [92].

Guardant360 (G360, Guardant Health; www.guardanthealth.com) platform has been designed to identify tumor-related genomic alterations via complete exon sequencing in 73 different genes in cfDNA from blood [93, 94]. FoundationACT Liquid Biopsy Assay (F1, Foundation Medicine, Inc., http://www.FoundationMedicine.com) sequences the exons of 315 cancer-associated genes and introns from 28 genes involved in rearrangements. Both the F1 and G360 tests have high specificities (>99\%) but somewhat lower sensitivities [95, 96]. Using G360, Schwaederle and colleagues were able to identify actionable aberration, matched to an FDA-approved drug, in TP53, EGFR, MET, PIK3CA, and NOTCH1 in cfDNA of patients diagnosed with either lung, breast or glioblastoma. They also compared the concordance in genomic alterations between FFPE tissues and cfDNA and found that $35 \%$ ( 22 of the 63 patients) had $\geq 1$ alteration in common between the tissue and cfDNA. In contrast, of 222 healthy volunteers, only one had an aberration in TP53 [97].

However, full exploitation of NGS technology remains limited due to reduced efficiency by which regions of interest can be captured/enriched from cfDNA and the higher error rate of sequencing relative to the accuracy of ddPCR. Additionally, multiplexed PCR-based amplicon library preparation is needed for NGS which can introduce sequencing bias resulting in uneven read coverage and increase in the numbers of duplicate fragments present in the library [98]. ddPCR, also, seems to be better at detecting rare genetic variants, and is less susceptible to inhibitors when compared to real-time quantitative PCR [99].

Since tumor DNA is released into the blood stream during cell turnover, presence of high levels of cfDNA has also been associated with shorter median overall survival of patients. Current procedures for quantitative
cfDNA analysis include simple spectrophotometry [100] and qPCR of housekeeping genes. Quantitation of both single genes like CYC [59], hTERT [61], $\beta 2$ microglobulin [26, 101], or multiple genes [82] in plasma samples has been used to quantitate cfDNA. Commercially available DNA DipStick TM Kit (Thermo Fisher Scientific) is, another, simple kit for qualitative assessment of cfDNA levels. Using the dip stick, Sozzi et al. [102], showed a reduction in cfDNA levels in the relapse-free NSCLC patients, and increasing levels in patients who subsequently presented with recurrence.

\section{Methods to isolate and identify CTC}

CTCs have been purified from biological fluids and in vitro cell cultures using a variety of strategies and techniques. But CTC detection rates are generally low despite the advances in cell capture technologies [103]. However, even the simple readout of presence or absence of CTC correlates with micro-metastases or early tumor cell dissemination which are events key to developing metastatic disease. Studies done by different groups like Olsson et al. [104], and Coumans and Terstappen [105] suggest that increased CTC detection precede clinical detection of metastasis in patients with an average lead time of at least a year or less, whereas patients with long-term disease-free survival had undetectable CTC postoperatively. In a study of 231 patients with metastatic castration-resistant prostate cancer, de Bono and colleagues [106] reported that $57 \%$ of patients had $\geq 5$ CTCs per $7.5 \mathrm{ml}$ of blood. Others too have found similar CTC counts in blood [107].

A number of methods have been evaluated for separation of CTCs. As CTCs differ in size from other blood components, size-based filtration systems have been frequently used by numerous authors to enrich them [108]. Generally, the filtration system consists of a filtration tube containing the membrane, a manifold vacuum plate with valve settings, a vacuum manifold and a vacuum pump [109-111]. Following filtration, CTCs can be stained by standard immuhistochemistry techniques to identify specific proteins or nucleic acid can be extracted and analyzed by ddPCR or NGS to identify mutations [107, 112-114]. Oh and coworkers used a high-density microporous chip filter to enrich CTCs and evaluate its clinical utility in colorectal cancer. CTCs were stained with a 4-color protocol involving DAPI for nucleated cells, CD45 monoclonal antibody (mAb) as a leukocyte marker, and epithelial cell adhesion molecule (EpCAM) $\mathrm{mAb}$, and cytokeratin (CK) $\mathrm{mAb}$ as an epithelial cell marker. In a study of 50 patients, CTC levels were at least four times higher in patients with stage IV cancer compared to patients with lower stages of cancer and healthy control subjects. Progression-free survival was lower in CTC+ patients compared with CTC- patients. 
In patients with stage I to III cancer, recurrence occurred only in CTC+ patients [115].

More recently, CTC isolation techniques have depended on antibodies against EpCAM, a protein that sticks out of the outer surface of CTCs, but not in healthy blood cells. The CellSearch CTC test, the only US FDA-approved CTC isolation platform consists of EpCAM antibodies attached to magnetic beads [116] so the cells can be pulled out of solution with a magnetic field. Presence of CellSearch CTCs have predicted the worst outcome in various cancers $[117,118]$. Longitudinal analyses have, also, identified a link between the size of CTC-clusters and patient overall survival. Compared to the patients without any CTC, those with 2-cell CTC-clusters and $\geq 3$-cell CTCclusters had a hazard ratio of 7.96 and 14.50 respectively $[119,120]$. Isolation of CTC with CellSearch CTC kit coupled with NGS on Roche 454 GS junior platform has proved successful in EGFR mutation analysis in the Phase II Erlotinib TRIGGER) study [121]. But studies on KRAS expression in CTC isolated by CellSearch did not find any statistically significant difference in clinical outcome between EGFR mutation-positive and EGFR mutationnegative patients tested for cetuximab efficacy in advanced colorectal cancer [122]. Similarly, CTC numbers did not correlate with clinical characteristics or patient outcomes in newly-diagnosed and recurrent ovarian cancer patients [123].

A major drawback of EpCAM based platform is the high variation in the gene expression between tumor subtypes and its downregulation during epithelial-tomesenchymal transition (EMT) of cancer cells [124]. Therefore, EpCAM based platforms have provided only modest sensitivity in detecting CTCs [125]. Unlike CellSearch system, AdnaTest EMT-2 (Qiagen) test is an immuno-magnetic bead enrichment step targeting the surface proteins EpCAM, HER2 and EGFR. Use of three proteins to capture CTC seems to be better than EpCAM alone. In the patient cohort of Hanssen and colleagues, CellSearch system identified CTCs only in patients with lymph node metastases or larger primary tumors ( $\geq \mathrm{T} 3)$. In contrast, multiplex RT-PCR for PIK3CA, AKT2, TWIST, and ALDH1 following AdnaTest EMT-2 capture, identified CTCs with the same frequency in both lymph node positive and negative patients [126]. Alonso-Alconada and colleagues have designed and patented PrediCTC for the assessment of CTC in metastatic colorectal cancer patients. The assay evaluates the expression of LOXL3, ZEB2, GAPDH, VIL1, TIMP1, CLU and TLN1 of captured CTCs [127].

Perhaps due to limitations in their detections technologies, KRAS mutant cfDNA was detected in patients with both resectable and advanced pancreatic disease whereas CTC was detected only in patients who had metastatic disease [4]. Therefore many authors have used modified kits to increase the specificity of these commercial kits. Antonarakis and co-workers [128] and Steinestel and group [129] found that including primers to detect specific splice variants or point mutations of androgen receptor in the AdnaTest gave more reliable information on cells resistant to drugs that target androgen receptor signaling. Others have taken advantage of the fact that CellSearch has one free channel position for addition of an extra antibody. Lindsay and colleagues added FITC-labelled anti-vimentin antibody or anti-Ki67 antibody to the free channel in the CellSearch system to fish out CTCs that were positive for vimentin or Ki67. Though only $32 \%$ and $45 \%$ of the CTC were positive for vimentin or Ki67 respectively, the presence of either vimentin + or Ki67+ CTC correlated with significantly reduced overall survival [130]. Recently Chikaishi and group developed a novel microfluidic platform, a 'CTC-chip' comprised of light-curable resins that has a unique advantage to bind any antibody. Using CTCchip coated with an anti-podoplanin antibody, they successfully captured human mesothelioma cells (ACC-MESO-4) with no EpCAM expression, but with podoplanin expression [125].

NGS analysis has revealed mutational heterogeneity in actionable genes between individual CTCs [131]. In order to circumvent the issue of heterogeneous expression of EpCAM on tumor cells, Bulfoni and group adopted a CTC enrichment strategy based on red blood cell lysis followed by the immunomagnetic depletion of leukocytes from blood samples (i.e., a negative selection) and subsequently stained the recovered cells with a cocktail of antibodies recognizing epithelial and mesenchymal markers and sorted them by multiparametric fluorescence. They found presence of CTCs co-expressing epithelial and mesenchymal markers (EM CTC) were significantly associated with poorer progression free survival and overall survival [132]. Zhang et al. [133], used anti-CD45 antibodies to deplete CD45 positive cells and enrich CTCs in blood collected from pancreatic cancer patients followed by immune-staining of CK and CD45, DAPI and fluorescence in situ hybridization with the centromere of chromosome 8 (CEP8) probe to identify CTCs in 31 cases of pancreatic cancers, and 30 healthy individuals. With a cutoff value set at 2 CTC cells $/ 3.75 \mathrm{~mL}$ blood, the sensitivity and specificity in the diagnosis of pancreatic cancer was $68.18 \%$ and $94.87 \%$, respectively. During a one and a half year follow-up, CTC positive pancreatic cancer patients showed metastasis and worse survival rate.

Expression pattern of a 10-gene liver-specific transcript panel to amplify RNA in CTC, was used by Kalinich and group, to differentiate hepatocellular carcinoma (HCC) from other nonmalignant liver conditions. They used a CTC-iChip microfluidic device which depletes hematopoietic cells from blood by size-based exclusion of 
red blood cells, platelets, and plasma, followed by magnetic deflection of white blood cells tagged with magnetic bead-conjugated CD45, CD16, and CD66b antibodies for enrichment of CTCs. The transcript expression pattern was able to correctly distinguish $\mathrm{HCC}$ with $88 \%$ specificity and $50 \%$ sensitivity from other malignancies. Positive CTC scores declined in treated patients receiving therapy [134].

Due to challenges in obtaining enough CTCs from blood, culture of CTCs in conventional media [135] or into mice [136, 137], is also being attempted in hopes of obtaining sufficient amounts for molecular analysis. Cultured CTCs maintain a similar genomic profile compared with primary tumor tissues and maintain their ability to grow long-term in vitro and show tissue specific metastasis properties. EpCAM-negative breast cancer CTCs containing stem-cell properties (CD44 +/CD24-) have been isolated by multiparametric flow cytometry from blood of breast cancer patients. These cells possessed high competence to generate breast cancer brain metastasis in xenografts [138, 139]. Incidentally, breast cancer is the second most common cancer to metastasize to the brain and the prognosis of patient diagnosed with brain metastasis remains poor [140].

\section{Methods to isolate and identify exosomes}

The stability of miRNA in blood have encouraged several investigators to identify and develop clinically relevant miRNA signatures as liquid biopsy markers. Ultracentrifugation is the most common method for separation of exosomes and miRNAs from blood. Allenson and coworkers, who compared exosome-derived DNA to cfDNA in liquid biopsies of patients with pancreatic ductal adenocarcinoma, found higher percentage of detectable KRAS mutations in exosome DNA than previously reported for cfDNA. They isolated exosomes using serial ultracentrifugation and characterized them with electron microscopy, flow cytometry and particle analysis [141]. Concerns of contamination of protein/RNA/membrane aggregates arising from similarities in sedimentation properties during high-speed ultracentrifugation, have prompted some protocols to use sucrose density gradients or adjusting the centrifugation duration in a "swinging bucket" or "fixedangle" rotor for efficient separation of the exosomes from the protein- or lipid-aggregates [142, 143]. Helwa et al. [144], did a comparative study using differential ultracentrifugation and three commercial reagents (miRCURYTM exosome isolation kit (miRCURY) (Exiqon, Woburn, MA), ExoQuickTM Serum Exosome Precipitation Solution (ExoQuick) (System Biosciences, Mountain view, CA), and Total Exosome Isolation Reagent for serum (TEIR) (Life Technologies, Carlsbad, CA) for isolation of exosomes using different volumes of pooled and individual human serum. They found that commercial kits produced a significantly higher yield (80-300 fold) of exosomes from serum as compared to ultracentrifugation, irrespective of the starting serum volume.

Both KRAS G12D and TP53 R273H mutations have been detected in exosomal DNA from patients with pancreas-associated pathologies, including pancreatic ductal adenocarcinoma, chronic pancreatitis and intraductal papillary mucinous neoplasm compared to healthy human subjects [145]. A combined isolation and analysis of exosomal RNA and cfDNA (together referred to as "exoNA") seems to improve blood-based liquid biopsy for EGFR mutation detection in NSCLC patients. For exoNA, the sensitivity was $98 \%$ for detection of activating EGFR mutations and $90 \%$ for EGFR T790 M. The corresponding sensitivities for ctDNA by BEAMing were $82 \%$ for activating mutations and $84 \%$ for T790 M. In a subgroup of patients with intrathoracic metastatic disease, the sensitivity increased from $26 \%$ to $74 \%$ for activating mutations $(p=0.003)$ and from $19 \%$ to $31 \%$ for T790 M ( $p=0.5)$ when using exoNA for detection [146].

Similar to CTCs, exosomes carry surface markers from the cell of origin, which is exploited for enrichment strategies [147]. Rapid advancement of another novel method known as nanoscale fluorescence activated cell sorting call, or nanoFACS, has further advanced the methods of exosome isolation and sorting and allowed for the study of discrete, free, individual exosomes from bodily fluids [148]. Others have isolated exosomes using size exclusion chromatography [43]. Exosomes and other extracellular vesicles derived proteins are also a source of biomarkers that complement other approaches for tumor assessment. Vykoukal and colleagues isolated them from plasma by ultracentrifugation flotation through a multi-step density-gradient overlay and analysed then by mass-spectrometry. They found SRGN, TPM3, THBS1 and HUWE1 proteins could be used to distinguished lung adenocarcinoma cases from controls [149].

miRNeasy mini and microKits (Qiagen) seems to the most popular kits for isolation of exosome-incorporated miRNAs and cell-free miRNAs [43, 150].

\section{Limitations}

A major bottleneck preventing the routine clinical use of liquid biopsy are the variations of cells and genetic material in the blood of patients [151], with tumor specific mutations ranging from undetectable in some patients to over hundred thousand copies of the mutation per $\mathrm{ml}$ of plasma in others with advanced disease [152]. Additionally, the accuracy of these tests is grossly influenced by the quality and quantity of the DNA extracted from the tissues. Thus, mutation can be missed in cases of contamination, widespread necrosis, or when only small quantities of DNA are available [153]. Perhaps for the 
same reason, there is a lack of consistent and robust results of circulating genomic materials, with many apparently contradictory reports in the literature [154]. Lee and group [107] found one of their patients had all COSMIC mutations though the patient was negative for EpCAM-positive CTCs. In another instance, the patient tested negative for all COSMIC mutations despite having the highest number of EpCAM-positive cells. COSMIC is an Ion AmpliSeq ${ }^{\text {mi }}$ Cancer Hotspot Panel v2, a nextgeneration sequencing assay from Thermo Fisher Scientific, Inc. that can detect 2800 Catalogue of Somatic Mutations in Cancer (COSMIC) across 50 genes [107]. Similarly, some studies have found very low mutation rate in cfDNA compared to tissues. KRAS mutations in plasma was $3 \%$ compared with $45 \%$ rate observed in the matched tissues from colorectal adenocarcinoma and colorectal high-grade intraepithelial neoplasia [61].

The ability of tumor cells to rapidly undergo EMT is an added confounding factor in obtaining reproducible results at various time points. During EMT, epithelial cells acquire mesenchymal, fibroblast-like properties and show reduced intercellular adhesion and increased motility [155]. Under physiological conditions, it increases the ability of the tumor cells to survive in blood circulation and establish micro-metastases in peripheral tissues. The process has been implicated in acquiring resistance to anti-cancer therapy and metastasis seen in resistant tumors [156].

Another limitation challenging the promise of liquid biopsy is the presence of mutations at higher frequency in cfDNA in benign or premalignant conditions compared to their malignant higher stage counterparts. Many of these genes traditionally fall under the category of hallmark drivers of cancers. Benign and premalignant conditions of various cancers express higher frequencies of alterations in BRAF, RAS, EGFR, HER2, FGFR3, PIK3CA, TP53, CDKN2A, and NF1/2 genes as compared to malignant tissues. Similarly, human HER2 is more commonly overexpressed in ductal carcinoma in situ $(\sim 27 \%-56 \%)$ when compared with invasive breast cancer [157]. Though Uehiro and colleagues were able to predict early cancers with high sensitivity and specificity using their prediction model, they did not find any significant trend toward a higher detection index in patients with advanced stage breast cancer [82].

Blood processing delays, storage, temperature, agitation of the sample and shipment are also a major source of variability between samples [158]. Because of the potential for cell lysis during blood coagulation during serum collection, plasma is often preferred over serum [159]. In addition, the choice of anti-coagulant used in plasma collection can influence downstream detection technologies, such as qRT-PCR [160]. Half-life of these circulating species in blood is also a matter of concern.
For example, the half-life of cfDNA in circulation ranges from few minutes to several hours [161]. An authors' choice of using either plasma or serum and their volumes seems to be guided by availability of blood samples. Similarly not all authors have mentioned if they quantified the amount of extracted cfDNA. Some authors quantified the purified cfDNA by using a spectrometer [54] while others normalized the concentration based on internal controls such as the mean of multiple $[49,82]$ or single genes $[26,59,61,101]$. Knowing the concentration of cfDNA is important as Zhang and coworkers [162] found a decline in sensitivity from $82.6 \%$ to $46.7 \%$ with decreasing cfDNA inputs $(p=0.028)$. Similarly, pre-analytical factors like sample collection tube type, incubation time, centrifugation steps, plasma input volume and DNA extraction kits had a major impact on the cfDNA recovery [163]. Helwa and group [144] found a linear relationship between input serum volume and isolated exosomes. Thus, low copy number of mutant alleles and low half-life of cfDNA, together with exclusion of finer experimental details, prevent reproducibility of analysis. Most studies that have investigated the use of circulating DNA to identify tumor genotype have included a small number of patients, further restricting their relevance and ability to investigate potential genotype-clinical outcome correlations [68].

\section{Laboratory to bedside success stories}

In spite of the limitations there are several advantages of liquid biopsy over tissue biopsy and has proved useful in monitoring of the metastatic burden of cancer. In cases when tissue biopsy is unfeasible or risky, a liquid biopsy gives the much needed information with a simple, minimally, invasive test. If not enough tissue is obtained from an initial biopsy for establishing biomarker status, liquid biopsy allows the patient to avoid repeat surgical biopsies. When cancer recurs after treatment, a liquid biopsy can re-establish biomarker status and see whether clinically significant changes have taken place in the new tumor. This information is important to plan the treatment options for the patient in whom the cancer has reoccurred. When cancer spreads to an area that is not easily reachable, a biopsy at the site of origin may not give correct information. A liquid biopsy on the other hand could give a more complete understanding of metastasis. Thus, the patient can get optimal care with a simple blood analysis. The advantages of liquid biopsy over traditional tissue biopsy is listed in Table 1.

A recent large study comparing the effectiveness of cfDNA analysis to tissue biopsy in NSCLC shows the clinical value of the liquid biopsy approach. The authors used the Therascreen EGFR RGQ PCR kit to detect L858R, Del19, and T790 M in plasma samples enrolled in phase IV, open-label, single-arm clinical trial of 
Table 1 Advantages of liquid biopsy over standard tissue biopsy

\begin{tabular}{|c|c|c|}
\hline & Liquid biopsy & Tissue biopsy \\
\hline Clinical sample & Blood & Effected tissue \\
\hline Risk & Minimal risk/pain & $\begin{array}{l}\text { Risk depends on location } \\
\text { of tumor }\end{array}$ \\
\hline $\begin{array}{l}\text { Ease of collecting } \\
\text { sample }\end{array}$ & Quick & $\begin{array}{l}\text { Depends on location of } \\
\text { tumor. } \\
\text { Some tumors are hard to } \\
\text { reach }\end{array}$ \\
\hline $\begin{array}{l}\text { Ease of } \\
\text { monitoring patients }\end{array}$ & Simple blood test & $\begin{array}{l}\text { Difficult to do repeat } \\
\text { surgeries; also surgeons } \\
\text { may not know where to } \\
\text { look for metastatic } \\
\text { tumor }\end{array}$ \\
\hline Invasive & Minimally invasive & Invasive \\
\hline $\begin{array}{l}\text { Time for patient } \\
\text { recovery }\end{array}$ & $\begin{array}{l}\text { Quick; does not } \\
\text { require hospitalization }\end{array}$ & $\begin{array}{l}\text { Time Intensive; requires } \\
\text { hospitalization of patients }\end{array}$ \\
\hline
\end{tabular}

Caucasian patients with NSCLC on first-line Gefitinib. The median progression-free survival (months) was 9.7 for mutation-positive tumor and 10.2 for mutationpositive tumor and plasma. The high concordance (94.3\%), test specificity (65.7\%), and test sensitivity (99.8\%) between matched tumor and plasma, further established that EGFR mutation status in tumor tissue can be accurately assessed using cfDNA [164]. This positive result led to the approval of the use of cfDNA analysis for EGFR mutation analysis for IRESSA $^{\circ}$ in Europe (in patients where a tumor sample was not evaluable), making it the first EGFR tyrosine kinase inhibitor for which cfDNA testing is included in the label. Similarly, Cobas ${ }^{\oplus}$ EGFR Mutation Test v2 (US-IVD) is a recent US FDA approved platform intended to aid physicians in identifying NSCLC patients with EGFR- Del 19 for treatment with TARCEVA ${ }^{\star}$ (Erlotinib) or patients with EGFR T790 M substitutions for TAGRISSO ${ }^{\text {im }}$ (Osimertinib) therapy. The US FDA has given approval for detection of these mutations using Cobas $^{\circledR}$ either in DNA isolated from FFPE tumor tissue or cfDNA from plasma derived from EDTA anti-coagulated peripheral whole blood in patients from whom a tumor biopsy cannot be obtained (http://www.accessdata.fda.gov/cdrh_do cs/pdf15/P150047a.pdf).

Biocept, Inc. is a San Diego, California-based molecular oncology diagnostics company that specializes in CTC and biomarker analysis. Using proprietary liquid biopsy based technology, therapeutic markers for breast cancer were identified from blood though tissue biopsy was found to be negative for such markers (http://biocept.com/patients/success-stories/). Such identification of targetable molecules allow for early initiation of appropriate therapies against a tumor which has accumulated fewer oncogenic events.

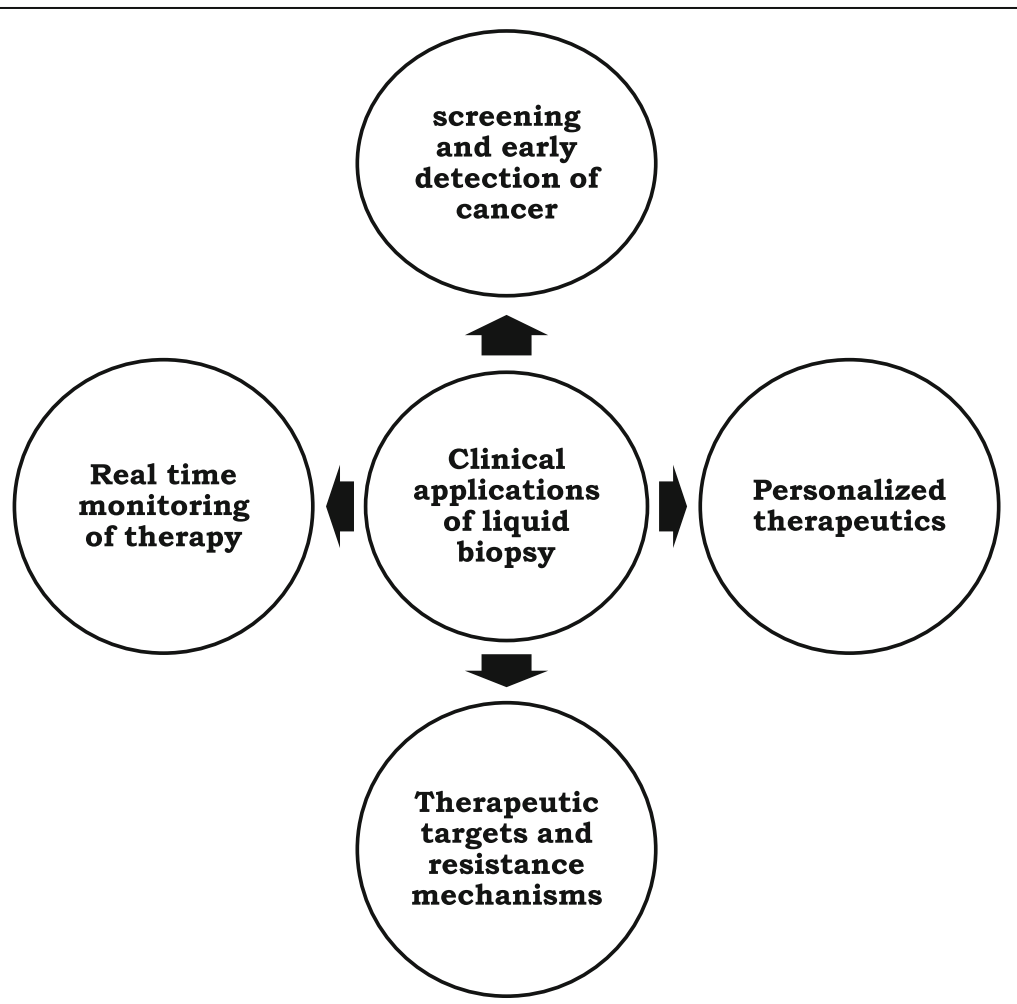

Fig. 3 Clinical application of liquid biopsy for personalized medicine. Capture of CTCs, ctDNA and exosomes as a "liquid biopsy" has several promising advantages over standard biopsy pertinent to clinical settings 
In another published case report, a 70 year old woman with no relevant past medical history diagnosed with stage IV NSCLC, (adenocarcinoma histotype) was found to harbor an Del19 EGFR activating mutation in her exosome DNA. The patient was treated with Gefitinib and was found to respond to the treatment with stabilization of disease and an improvement in quality of her life within 10 months [165].

\section{Conclusion}

Cancer is a heterogeneous disease that is continuously evolving during its progression making clinical management difficult. To date, tissue biopsy remains the only option to identify targetable markers present in the tissue, but the procedure has inherent deficiencies which prevent identification of all such markers in a biopsied tissue. Although technically challenging, an advantage of liquid biopsies over other traditional tissue based methodologies is the enablement of longitudinal monitoring which could help clinical oncologists gain a broader molecular understanding of the disease (Fig. 3). Based on detection of specific alterations in the dying tissues contributing to the cells and DNA circulating in blood, it might be possible to diagnose disease even before the onset of clinical symptoms or progression to later, more advanced stages, where the disease burden becomes high, and is typically hard to manage or untreatable. Thus, liquid biopsy has tremendous potential as a non-invasive blood-based diagnostic test for personalized care of cancer patients.

\section{Future perspective}

There is a critical need for identifying specific signatures present in the ever evolving cancer cells for improved analytical and diagnostic sensitivity. Studies conducted within the past decade have shown that circulating tumor derived cells, DNA, or RNA in the blood harbor genetic alterations that correspond to primary tumors and metastatic sites. They hold the promise of providing a comprehensive realtime picture of the complete tumor burden in an individual patient. Despite current advances, it is not known if they are representative of all relevant primary and metastatic cell clones. Similarly, not much is known about the biological processes that shed these biomarkers into blood. Their clinical utility is restricted by the available technologies for collection, storage and isolation from blood. However, in the next few years technological refinements should allow us to further study these processes in depth and bring about a fundamental change in cancer management.

\section{Acknowledgements}

JA and SS would like to thank Director, AlIMS-Raipur and Dr. Eli Mohapatra, Professor and Head, Department of Biochemistry, AlIMS-Raipur for their support and encouragement. The authors would also like to thank Mr. Eric Paz, Head of Genotyping, ReproCELL USA Inc., Maryland, USA, for grammatical editing of the manuscript.
Funding

The work is supported by an intramural grant from AllMS-Raipur (No. AlIMSRPR/ IEC/2017/106) to JA.

\section{Availability of data and materials}

Data sharing not applicable to this article as no datasets were generated or analyzed during the current study.

\section{Authors' contributions}

This is a review and all the authors contributed to writing the review. All authors read and approved the final manuscript.

Ethics approval and consent to participate

Not applicable

Consent for publication

Not applicable

\section{Competing interests}

The authors declare that they have no competing interests.

\section{Publisher's Note}

Springer Nature remains neutral with regard to jurisdictional claims in published maps and institutional affiliations.

\section{Author details}

${ }^{1}$ Department of Biochemistry, All India Institute of Medical Sciences, Raipur, Chhattisgarh 492099, India. '2Department of Surgery, All India Institute of Medical Sciences, Raipur, Chhattisgarh 492099, India. ${ }^{3}$ Department of Surgical Oncology, Tata Memorial Hospital, Parel, Mumbai 400 012, India.

Received: 21 December 2017 Accepted: 5 January 2018

Published online: 24 January 2018

\section{References}

1. Kim ES, Hirsh V, Mok T, et al. Gefitinib versus docetaxel in previously treated non-small-cell lung cancer (INTEREST): a randomised phase III trial. Lancet. 2008;372(9652):1809-18

2. Hidalgo M. Pancreatic cancer. N Engl J Med. 2010;362(17):1605-17.

3. Brouwer A, De Laere B, Peeters D, et al. Evaluation and consequences of heterogeneity in the circulating tumor cell compartment. Oncotarget. 2016; 7(30):48625-43.

4. Earl J, Garcia-Nieto S, Martinez-Avila JC, et al. Circulating tumor cells (Ctc) and kras mutant circulating free Dna (cfdna) detection in peripheral blood as biomarkers in patients diagnosed with exocrine pancreatic cancer. BMC Cancer. 2015;15:797

5. Kamisawa T, Wood LD, Itoi T, Takaori K. Pancreatic cancer. Lancet. 2016:388: 73-85.

6. Takai $\mathrm{E}$, Yachida S. Circulating tumor DNA as a liquid biopsy target for detection of pancreatic cancer. World J Gastroenterol. 2016;22(38):8480-8.

7. Martin TA, Ye L, Sanders AJ, Lane J, Jiang WG. Cancer invasion and metastasis: molecular and cellular perspective. Metastatic cancer: clinical and biological perspectives, Madame Curie Bioscience Database edited by Rahul Jandial. @2013 Landes Bioscience. https://www.ncbi.n/m.nih.gov/books/ NBK164700/. Accessed 9 Jan 2018.

8. Spindler KL, Appelt AL, Pallisgaard N, et al. Cell-free DNA in healthy individuals, noncancerous disease and strong prognostic value in colorectal cancer. Int J Cancer. 2014:135(12):2984-91.

9. Hsieh CC, Hsu HS, Chang SC, Chen YJ. Circulating cell-free DNA levels could predict oncological outcomes of patients undergoing Esophagectomy for esophageal squamous cell carcinoma. Int J Mol Sci. 2016;17(12). (PMID: 27999323)

10. Ilie M, Hofman V, Long $\mathrm{E}$, et al. Current challenges for detection of circulating tumor cells and cell-free circulating nucleic acids, and their characterization in non-small cell lung carcinoma patients. What is the best blood substrate for personalized medicine? Ann Transl Med. 2014;2(11):107.

11. Ashworth TR. A case of cancer in which cells similar to those in the tumours were seen in the blood after death. Aust Med J. 1869;14:146-7.

12. Engell HC. Cancer cells in the circulating blood; a clinical study on the occurrence of cancer cells in the peripheral blood and in venous blood 
draining the tumour area at operation. Actachirurgica Scandinavica Supplementum. 1955;201:1-70.

13. Ilié $M$, Hofman P. Pros: can tissue biopsy be replaced by liquid biopsy? Transl Lung Cancer Res. 2016;5(4):420-3.

14. Zhang Z, Ramnath N, Nagrath S. Current status of CTCS as liquid biopsy in lung cancer and future directions. Front Oncol. 2015;5:209.

15. Agelaki S, Dragolia M, Markonanolaki H, et al. Phenotypic characterization of circulating tumor cells in triple negative breast cancer patients. Oncotarget. 2017;8(3):5309-22

16. Shaw JA, Guttery DS, Hills A, et al. Mutation analysis of cell-free DNA and single circulating tumor cells in metastatic breast cancer patients with high circulating tumor cell counts. Clin Cancer Res. 2017;23(1):88-96.

17. Sonpavde G, Antonarakis ES. Circulating tumor cells in advanced prostate cancer: time to move from prognostic to predictive ability. Eur Urol. 2017; 71(2):172-3.

18. Zhao R, Cai Z, Li S, et al. Expression and clinical relevance of epithelial and mesenchymal markers in circulating tumor cells from colorectal cancer. Oncotarget. 2016; https://doi.org/10.18632/oncotarget.14065. [Epub ahead of print]

19. Allard WJ, Matera J, Miller MC, et al. Tumor cells circulate in the peripheral blood of all major carcinomas but not in healthy subjects or patients with nonmalignant diseases. Clin Cancer Res. 2004;10:6897-904.

20. Kim MY, Oskarsson T, Acharyya S, et al. Tumor self-seeding by circulating cancer cells. Cell. 2009;139:1315-26.

21. Flores LM, Kindelberger DW, Ligon AH, et al. Improving the yield of circulating tumour cells facilitates molecular characterisation and recognition of discordant HER2 amplification in breast cancer. $\mathrm{Br} J$ Cancer. 2010;102(10):1495-502

22. Li Kong S, Liu X, Mohamed Suhaimi NA, et al. Molecular characterization of circulating colorectal tumor cells defines genetic signatures for individualized cancer care. Oncotarget. 2017; [Epub ahead of print]

23. Mandel $P$, Metais $P$. Les acidesnucleiques du plasma sanguin chez l'homme. C R Seances Soc Biol Fil. 1948;142:241-3.

24. Malapelle U, Pisapia P, Rocco D, et al. Next generation sequencing techniques in liquid biopsy: focus on non-small cell lung cancer patients. Transl Lung Cancer Res. 2016;5(5):505-10.

25. Mok T, Wu YL, Lee JS, et al. Detection and dynamic changes of EGFR mutations from circulating tumor DNA as a predictor of survival outcomes in NSCLC patients treated with first-line intercalated erlotinib and chemotherapy. Clin Cancer Res. 2015;21(14):3196-203.

26. Nygaard AD, Spindler KL, Pallisgaard N, Andersen RF, Jakobsen A. Levels of cell-free DNA and plasma KRAS during treatment of advanced NSCLC. Oncol Rep. 2014;31(2):969-74.

27. Jahr S, Hentze H, Englisch S, et al. DNA fragments in the blood plasma of cancer patients: quantitations and evidence for their origin from apoptotic and necrotic cells. Cancer Res. 2001;61(4):1659-65.

28. Diaz LA Jr, Bardelli A. Liquid biopsies: genotyping circulating tumor DNA. J Clin Oncol. 2014;32:579-86.

29. Bettegowda C, Sausen M, Leary RJ, et al. Detection of circulating tumor DNA in early- and late-stage human malignancies. Sci Transl Med. 2014;6: 224 ra24.

30. Medina Diaz I, Nocon A, Mehnert DH, et al. Performance of StreckcfDNA blood collection tubes for liquid biopsy testing. PLoS One. 2016;11(11): e0166354

31. Kang Q, Henry NL, Paoletti C, et al. Comparative analysis of circulating tumor DNA stability in K3EDTA, Streck, and CellSave blood collection tubes. Clin Biochem. 2016:49(18):1354-60.

32. Valentino A, Reclusa P, Sirera R, et al. Exosomal microRNAs in liquid biopsies: future biomarkers for prostate cancer. Clin Transl Oncol. 2017; https://doi. org/10.1007/s12094-016-1599-5.

33. Skog J, Würdinger T, van Rijn S, et al. Glioblastoma microvesicles transport RNA and proteins that promote tumour growth and provide diagnostic biomarkers. Nat Cell Biol. 2008;10:1470-6.

34. Beach A, Zhang HG, Ratajczak MZ, Kakar SS. Exosomes: an overview of biogenesis, composition and role in ovarian cancer. J Ovarian Res. 2014;7:14.

35. Gasch C, Plummer PN, Jovanovic L, et al. Heterogeneity of miR-10b expression in circulating tumor cells. Sci Rep. 2015;5:15980.

36. Reclusa $P$, Sirera $R$, Araujo A, et al. Exosomes genetic cargo in lung cancer: a truly Pandora's box. Transl Lung Cancer Res. 2016;5(5):483-91.

37. Okajima W, Komatsu S, Ichikawa D, et al. Circulating microRNA profiles in plasma: identification of miR-224 as a novel diagnostic biomarker in hepatocellular carcinoma independent of hepatic function. Oncotarget. 2016;7(33):53820-36.

38. Lou N, Ruan AM, Qiu B, et al. miR-144-3p as a novel plasma diagnostic biomarker for clear cell renal cell carcinoma. Urol Oncol. 2017;35(1):36. e7-36.e14.

39. Li G, Zhao A, Péoch M, Cottier M, Mottet N. Detection of urinary cell-free miR-210 as a potential tool of liquid biopsy for clear cell renal cell carcinoma. Urol Oncol. 2017;35(5):294-99.

40. Komatsu S, Ichikawa D, Kawaguchi T, et al. Circulating miR-21 as an independent predictive biomarker for chemoresistance in esophageal squamous cell carcinoma. Am J Cancer Res. 2016;6(7):1511-23.

41. Fan L, Qi H, Teng J, et al. Identification of serum miRNAs by nanoquantum dots microarray as diagnostic biomarkers for early detection of non-small cell lung cancer. Tumour Biol. 2016;37(6):7777-84.

42. Koutova L, Sterbova M, Pazourkova $E$, et al. The impact of standard chemotherapy on miRNA signature in plasma in AML patients. Leuk Res. 2015;39(12):1389-95.

43. Endzeliņš $E$, Berger $A$, Melne $V$, et al. Detection of circulating miRNAs: comparative analysis of extracellular vesicle-incorporated miRNAs and cell-free miRNAs in whole plasma of prostate cancer patients. BMC Cancer. 2017:17(1):730.

44. Pérez-Barrios C, Nieto-Alcolado I, Torrente M, et al. Comparison of methods for circulating cell-free DNA isolation using blood from cancer patients: impact on biomarker testing. Transl Lung Cancer Res. 2016; 5(6):665-72

45. Ibrahim IH, Kamel MM, Ghareeb M. Circulating DNA in Egyptian women with breast cancer. Asian Pac J Cancer Prev. 2016;17(6):2989-93.

46. Chan BA, Hughes BG. Targeted therapy for non-small cell lung cancer: current standards and the promise of the future. Transl Lung Cancer Res. 2015:4(1):36-54

47. Suda K, Onozato R, Yatabe Y. Mitsudomi T.EGFR T790M mutation: a double role in lung cancer cell survival? J Thorac Oncol. 2009;4(1):1-4.

48. Walsh K, Wallace WA, Butler $\mathrm{R}$, et al. A cautionary lesson on the use of targeted methods for EGFR mutation analysis: a case report. J Clin Pathol. 2014;67(8):734-5.

49. Wu YL, Sequist $L V$, Hu CP, et al. EGFR mutation detection in circulating cellfree DNA of lung adenocarcinoma patients: analysis of LUX-lung 3 and $6 . \mathrm{Br}$ J Cancer. 2017:116(2):175-85.

50. Karachaliou N, Mayo-de las Casas C, Queralt C, et al. Association of EGFR L858R mutation in circulating free DNA with survival in the EURTAC trial. JAMA Oncol. 2015;1(2):149-57.

51. Yu Q, Huang F, Zhang M, et al. Multiplex picoliter-droplet digital PCR for quantitative assessment of EGFR mutations in circulating cell-free DNA derived from advanced non-small cell lung cancer patients. Mol Med Rep. 2017;16:1157-66.

52. Reck M, Hagiwara K, Han B, et al. ctDNA determination of EGFR mutation status in European and Japanese patients with advanced NSCLC: the ASSESS study. J Thorac Oncol. 2016;11(10):1682-9.

53. Dearden S, Brown H, Jenkins S, et al. EGFR T790M mutation testing within the osimertinib AURA phase I study. Lung Cancer. 2017;109:9-13.

54. Seki Y, Fujiwara Y, Kohno T, et al. Picoliter-droplet digital polymerase chain reaction-based analysis of cell-free plasma DNA to assess EGFR mutations in lung adenocarcinoma that confer resistance to tyrosine-Kinase inhibitors. Oncologist. 2016;21(2):156-64.

55. He M, Capelletti M, Nafa K, et al. EGFR exon 19 insertions: a new family of sensitizing EGFR mutations in lung adenocarcinoma. Clin Cancer Res. 2012; 18(6):1790-7.

56. Chabon JJ, Simmons AD, Lovejoy AF, et al. Circulating tumour DNA profiling reveals heterogeneity of EGFR inhibitor resistance mechanisms in lung cancer patients. Nat Commun. 2016;7:11815.

57. Misale S, Yaeger R, Hobor S, et al. Emergence of KRAS mutations and acquired resistance to anti-EGFR therapy in colorectal cancer. Nature. 2012; 486(7404):532-6.

58. Spindler KL, Pallisgaard N, Appelt AL, et al. Clinical utility of KRAS status in circulating plasma DNA compared to archival tumour tissue from patients with metastatic colorectal cancer treated with anti-epidermal growth factor receptor therapy. Eur J Cancer. 2015;51(17):2678-85.

59. Spindler KL, Pallisgaard N, Vogelius I, Jakobsen A. Quantitative cell-free DNA, KRAS, and BRAF mutations in plasma from patients with metastatic colorectal cancer during treatment with cetuximab and irinotecan. Clin Cancer Res. 2012;18(4):1177-85. 
60. Galanopoulos M, Papanikolaou IS, Zografos E, et al. Comparative study of mutations in single nucleotide polymorphism loci of KRAS and BRAF genes in patients who underwent screening colonoscopy, with and without premalignant intestinal polyps. Anticancer Res. 2017;37(2):651-7.

61. Perrone $F$, Lampis $A$, Bertan $C$, et al. Circulating free DNA in a screening program for early colorectal cancer detection. Tumori. 2014;100(2):115-21.

62. Thierry AR, Mouliere F, El Messaoudi S, et al. Clinical validation of the detection of KRAS and BRAF mutations from circulating tumor DNA. Nat Med. 2014;20(4):430-5.

63. Hertzman JC, Egyhazi BS. BRAF inhibitors in cancer therapy. Pharmacol Ther. 2014;142(2):176-82.

64. Janku F, Huang HJ, Claes B, et al. BRAF mutation testing in cell-free DNA from the plasma of patients with advanced cancers using a rapid, automated molecular diagnostics system. Mol Cancer Ther. 2016;15(6):1397-404.

65. Sanmamed MF, Fernández-Landázuri S, Rodríguez C, et al. Quantitative cell-free circulating BRAFV600E mutation analysis by use of droplet digital PCR in the follow-up of patients with melanoma being treated with BRAF inhibitors. Clin Chem. 2015;61(1):297-304.

66. Yamada $\mathrm{T}$, Iwai $\mathrm{T}$, Takahashi $\mathrm{G}$, et al. Utility of KRAS mutation detection using circulating cell-free DNA from patients with colorectal cancer. Cancer Sci. 2016;107(7):936-43.

67. Yokota T. Are KRAS/BRAF mutations potent prognostic and/or predictive biomarkers in colorectal cancers? Anti Cancer Agents Med Chem. 2012; 12(2):163-71.

68. Tabernero J, Lenz HJ, Siena S, et al. Analysis of circulating DNA and protein biomarkers to predict the clinical activity of regorafenib and assess prognosis in patients with metastatic colorectal cancer: a retrospective, exploratory analysis of the CORRECT trial. Lancet Oncol. 2015;16(8):937-48.

69. Bennett CW, Berchem G, Kim YJ, El-Khoury V. Cell-free DNA and nextgeneration sequencing in the service of personalized medicine for lung cancer. Oncotarget. 2016;7(43):71013-35.

70. Morgan SR, Whiteley J, Donald E, et al. Comparison of KRAS mutation assessment in tumor DNA and circulating free DNA in plasma and serum samples. Clin Med Insights Pathol. 2012;5:15-22.

71. Higgins MJ, Jelovac D, Barnathan E, et al. Detection of tumor PIK3CA status in metastatic breast cancer using peripheral blood. Clin Cancer Res. 2012; 18(12):3462-9.

72. Janku F, Angenendt $\mathrm{P}$, Tsimberidou AM, et al. Actionable mutations in plasma cell-free DNA in patients with advanced cancers referred for experimental targeted therapies. Oncotarget. 2015;6(14):12809-21.

73. Duan H, Lu J, Lu T, et al. Comparison of EGFR mutation status between plasma and tumor tissue in non-small cell lung cancer using the Scorpion ARMS method and the possible prognostic significance of plasma EGFR mutation status. Int J Clin Exp Pathol. 2015;8(10):13136-45.

74. Adamo P, Cowley CM, Neal CP, et al. Profiling tumour heterogeneity through circulating tumour DNA in patients with pancreatic cancer Oncotarget. 2017:8(50):87221-33.

75. Grasselli J, Elez E, Caratù G, et al. Concordance of blood- and tumor-based detection of RAS mutations to guide anti-EGFR therapy in metastatic colorectal cancer. Ann Oncol. 2017;28(6):1294-301.

76. Brychta N, Krahn T, von Ahsen O. Detection of KRAS mutations in circulating tumor DNA by digital PCR in early stages of pancreatic cancer. Clin Chem. 2016;62(11):1482-91.

77. Srinivasan M, Sedmak D, Jewell S. Effect of fixatives and tissue processing on the content and integrity of nucleic acids. Am J Pathol. 2002;161(6): 1961-71.

78. Vanni I, Coco S, Truini A, et al. Next-generation sequencing workflow for NSCLC critical samples using a targeted sequencing approach by ion torrent PGM ${ }^{\mathrm{TM}}$ platform. Int J Mol Sci. 2015;16(12):28765-82.

79. Page K, Guttery DS, Fernandez-Garcia D, et al. Next generation sequencing of circulating cell-free DNA for evaluating mutations and gene amplification in metastatic breast cancer. Clin Chem. 2017:63(2):532-41.

80. Takeshita T, Yamamoto Y, Yamamoto-lbusuki M, et al. Clinical significance of monitoring ESR1 mutations in circulating cell-free DNA in estrogen receptor positive breast cancer patients. Oncotarget. 2016;7(22):32504-18.

81. Guttery DS, Page K, Hills A, et al. Noninvasive detection of activating estrogen receptor 1 (ESR1) mutations in estrogen receptor-positive metastatic breast cancer. Clin Chem. 2015;61(7):974-82

82. Uehiro N, Sato F, Pu F, Tanaka S, Kawashima M, Kawaguchi K, Sugimoto M, Saji S, Toi M. Circulating cell-free DNA-based epigenetic assay can detect early breast cancer. Breast Cancer Res. 2016;18(1):129.
83. Cree IA. Diagnostic RAS mutation analysis by polymerase chain reaction (PCR). Biomol Detect Quantif. 2016;8:29-32.

84. D'Haene N, Le Mercier M, De Nève N, et al. Clinical validation of targeted next generation sequencing for colon and Lung cancers. PLoS One. 2015; 10(9):e0138245

85. Chang F, Li MM. Clinical application of amplicon-based next-generation sequencing in cancer. Cancer Genet. 2013;206(12):413-9.

86. Malapelle U, Vigliar E, Sgariglia R, et al. Ion Torrent next-generation sequencing for routine identification of clinically relevant mutations in colorectal cancer patients. J Clin Pathol 2015;68(1):64-68.

87. Scarpa A, Sikora K, Fassan M, et al. Molecular typing of lung adenocarcinoma on cytological samples using a multigene next generation sequencing panel. PLoS One. 2013;8(11):e80478.

88. Palmirotta R, Lovero D, Silvestris $\mathrm{E}$, et al. Next-generation sequencing (NGS) analysis on single Circulating Tumor Cells (CTCS) with no need of Wholegenome Amplification (WGA). Cancer Genomics Proteomics. 2017;14(3):173-9.

89. Raymond CK, Hernandez J, Karr R, et al. Collection of cell-free DNA for genomic analysis of solid tumors in a clinical laboratory setting. PLoS One. 2017;12(4):e0176241.

90. Paweletz CP, Sacher AG, Raymond CK, et al. Bias-corrected targeted nextgeneration sequencing for rapid, multiplexed detection of actionable alterations in cell-free DNA from advanced lung cancer patients. Clin Cancer Res. 2016;22(4):915-22.

91. Malapelle U, Mayo de-Las-Casas C, Rocco D, et al. Development of a gene panel for next-generation sequencing of clinically relevant mutations in cell-free DNA from cancer patients. Br J Cancer. 2017;116(6):802-10.

92. Paasinen-Sohns A, Koelzer VH, Frank A, et al. Single-center experience with a targeted next generation sequencing assay for assessment of relevant somatic alterations in solid tumors. Neoplasia. 2017;19(3):196-206.

93. Yang M, Topaloglu U, Petty WJ, et al. Circulating mutational portrait of cancer: manifestation of aggressive clonal events in both early and late stages. J Hematol Oncol. 2017;10(1):100.

94. Lanman RB, Mortimer SA, Zill OA, et al. Analytical and clinical validation of a digital sequencing panel for quantitative, highly accurate evaluation of cell-free circulating tumor DNA. PLoS One. 2015;10(10):e0140712.

95. Kuderer NM, Burton KA, Blau S, et al. Comparison of 2 commercially available next-generation sequencing platforms in oncology. JAMA Oncol. 2017:3(7):996-8.

96. Chae YK, Davis AA, Carneiro BA, et al. Concordance between genomic alterations assessed by next-generation sequencing in tumor tissue or circulating cell-free DNA. Oncotarget. 2016;7(40):65364-73.

97. Schwaederle M, Husain H, Fanta PT, et al. Detection rate of actionable mutations in diverse cancers using a biopsy-free (blood) circulating tumo cell DNA assay. Oncotarget. 2016;7(9):9707-17.

98. Chen YC, Liu T, Yu CH, et al. Effects of GC bias in next-generationsequencing data on de novo genome assembly. PLoS One. 2013;8(4): e62856.

99. Huggett JF, Whale A. Digital PCR as a novel technology and its potential implications for molecular diagnostics. Clin Chem. 2013:59(12):1691-3.

100. Silva JM, Garcia JM, Dominguez G, et al. Persistence of tumor DNA in plasma of breast cancer patients after mastectomy. Ann Surg Oncol. 2002; $9(1): 71-6$

101. Gal S, Fidler C, Lo YM, et al. Quantitation of circulating DNA in the serum of breast cancer patients by real-time PCR. Br J Cancer. 2004;90(6):1211-5.

102. Sozzi G, Conte D, Mariani L, et al. Analysis of circulating tumor DNA in plasma at diagnosis and during follow-up of lung cancer patients. Cancer Res. 2001;61(12):4675-8.

103. Levy $\mathrm{B}, \mathrm{Hu} \mathrm{ZI}$, Cordova $\mathrm{KN}$, et al. Clinical utility of liquid diagnostic platforms in non-small cell lung cancer. Oncologist. 2016;21(9):1121-30.

104. Olsson E, Winter C, George A, et al. Serial monitoring of circulating tumor DNA in patients with primary breast cancer for detection of occult metastatic disease. EMBO Mol Med. 2015;7(8):1034-47.

105. Coumans F, Terstappen L. Detection and characterization of circulating tumor cells by the CellSearch approach. Methods Mol Biol. 2015;1347: 263-78.

106. de Bono JS, Scher HI, Montgomery RB, et al. Circulating tumor cells predict survival benefit from treatment in metastatic castration-resistant prostate cancer. Clin Cancer Res. 2008:14(19):6302-9.

107. Lee SJ, Lee $\mathrm{CH}$, Choi SH, et al. Evaluation of a novel approach to circulating tumor cell isolation for cancer gene panel analysis in patients with breast cancer. Oncol Lett. 2017;13(5):3025-31. 
108. Lim LS, Hu M, Huang MC, et al. Microsieve lab-chip device for rapid enumeration and fluorescence in situ hybridization of circulating tumor cells. Lab Chip. 2012;12:4388-96.

109. Wu S, Liu S, Liu Z, et al. Classification of circulating tumor cells by epithelialmesenchymal transition markers. PLoS One. 2015;10(4):e0123976.

110. Adebayo Awe J, Xu MC, Wechsler J, et al. Three-dimensional Telomeric analysis of isolated circulating tumor cells (CTCS) defines CTC subpopulations. Transl Oncol. 2013;6(1):51-65.

111. Zhang D, Zhao L, Zhou P, et al. Circulating tumor microemboli (CTM) and vimentin+ circulating tumor cells (CTCS) detected by a size-based platform predict worse prognosis in advanced colorectal cancer patients during chemotherapy. Cancer Cell Int. 2017;17:6. https://doi.org/10.1186/s12935016-0373-7.

112. Anantharaman A, Friedlander T, Lu D, et al. Programmed death-ligand 1 (PD-L1) characterization of circulating tumor cells (CTCS) in muscle invasive and metastatic bladder cancer patients. BMC Cancer. 2016;16(1):744.

113. Murray NP, Albarran V, Perez G, Villalon R, Ruiz A. Secondary circulating tumor cells (CTCS) but not primary CTCS are associated with the clinicopathological parameters in Chilean patients with colo-rectal cancer. Asian Pac J Cancer Prev. 2015;16(11):4745-9.

114. Ju M, Kao GD, Steinmetz D, et al. Application of a telomerase-based circulating tumor cell (CTC) assay in bladder cancer patients receiving postoperative radiation therapy: a case study. Cancer Biol Ther. 2014;15(6):683-7.

115. Oh BY, Kim J, Lee WY, Kim HC. A new size-based platform for circulating tumor cell detection in colorectal cancer patients. Clin Colorectal Cancer. 2017;

116. Riethdorf $S$, Fritsche $H$, Müller $V$, et al. Detection of circulating tumor cells in peripheral blood of patients with metastatic breast cancer: a validation study of the CellSearch system. Clin Cancer Res. 2007;13(3):920-8.

117. Busetto GM, Ferro M, Del Giudice F, et al. The prognostic role of circulating tumor cells (CTC) in high-risk non-muscle-invasive bladder cancer. Clin Genitourin Cancer. 2017;15(4):e661-6.

118. Messaritakis I, Politaki E, Plataki M, et al. Heterogeneity of circulating tumor cells (CTCS) in patients with recurrent small cell lung cancer (SCLC) treated with pazopanib. Lung Cancer. 2017;104:16-23.

119. Wang C, Mu Z, Chervoneva I, et al. Longitudinally collected CTCs and CTC clusters and clinical outcomes of metastatic breast cancer. Breast Cancer Res Treat. 2017;161(1):83-94.

120. Mu Z, Wang C, Ye Z, et al. Prospective assessment of the prognostic value of circulating tumor cells and their clusters in patients with advanced-stage breast cancer. Breast Cancer Res Treat. 2015;154(3):563-71.

121. Marchetti A, Del Grammastro M, Felicioni L, et al. Assessment of EGFR mutations in circulating tumor cell preparations from NSCLC patients by next generation sequencing: toward a real-time liquid biopsy for treatment. PLoS One. 2014;9(8):e103883.

122. Kuboki Y, Matsusaka S, Minowa S, et al. Circulating tumor cell (CTC) count and epithelial growth factor receptor expression on CTCS as biomarkers for cetuximab efficacy in advanced colorectal cancer. Anticancer Res. 2013; 33(9):3905-10

123. Liu JF, Kindelberger D, Doyle C, Lowe A, Barry WT, Matulonis UA. Predictive value of circulating tumor cells (CTCs) in newly-diagnosed and recurrent ovarian cancer patients. Gynecol Oncol. 2013;131(2):352-6.

124. Tadimety A, Syed A, Nie Y, et al. Liquid biopsy on chip: a paradigm shift towards the understanding of cancer metastasis. Integr Biol. 2017;9:22-49.

125. Chikaishi Y, Yoneda K, Ohnaga T, Tanaka F. EpCAM-independent capture of circulating tumor cells with a 'universal CTC-chip'. Oncol Rep. 2017;37(1):77-82.

126. Hanssen A, Wagner J, Gorges TM, et al. Characterization of different CTC subpopulations in non-small cell lung cancer. Sci Rep. 2016;6:28010.

127. Alonso-Alconada L, Barbazan J, Candamio S, et al. PrediCTC, liquid biopsy in precision oncology: a technology transfer experience in the Spanish health system. Clin Transl Oncol. 2017:

128. Antonarakis ES, Lu C, Wang H, et al. AR-V7 and resistance to enzalutamide and abiraterone in prostate cancer. N Engl J Med. 2014;371(11):1028-38.

129. Steinestel J, Luedeke $M$, Arndt A, et al. Detecting predictive androgen receptor modifications in circulating prostate cancer cells. Oncotarget. 2015;

130. Lindsay CR, Le Moulec S, Billiot F, et al. Vimentin and Ki67 expression in circulating tumour cells derived from castrate-resistant prostate cancer. BMC Cancer. 2016:16:168.

131. Bingham C, Fernandez SV, Fittipaldi $P$, et al. Mutational studies on single circulating tumor cells isolated from the blood of inflammatory breast cancer patients. Breast Cancer Res Treat. 2017;163(2):219-30.
132. Bulfoni M, Gerratana L, Del Ben F, et al. In patients with metastatic breast cancer the identification of circulating tumor cells in epithelial-tomesenchymal transition is associated with a poor prognosis. Breast Cancer Res. 2016;18(1):30

133. Zhang Y, Wang F, Ning N, et al. Patterns of circulating tumor cells identified by CEP8, CK and CD45 in pancreatic cancer. Int J Cancer. 2015;136(5):1228-33.

134. Kalinich M, Bhan I, Kwan TT, et al. An RNA-based signature enables high specificity detection of circulating tumor cells in hepatocellular carcinoma. Proc Natl Acad Sci U S A. 2017:114(5):1123-8.

135. Hwang $\mathrm{E}, \mathrm{Uh} \mathrm{JH}$, Lee $\mathrm{HS}$, et al. Cancer gene panel analysis of cultured circulating tumor cells and primary tumor tissue from patients with breast cancer. Oncol Lett. 2017;13(6):4627-32.

136. Yu M, Bardia A, Aceto N, et al. Cancer therapy. Ex vivo culture of circulating breast tumor cells for individualized testing of drug susceptibility. Science. 2014;345(6193):216-20.

137. Wanga R, Chu GCY, Mrdenovic S, et al. Cultured circulating tumor cells and their derived xenografts for personalized oncology. Asian J Urol. 2016;3(4): 240-53.

138. Vishnoi M, Peddibhotla S, Yin W, et al. The isolation and characterization of CTC subsets related to breast cancer dormancy. Sci Rep. 2015;5:17533.

139. Boral D, Vishnoi M, Liu HN, et al. Molecular characterization of breast cancer CTCs associated with brain metastasis. Nat Commun. 2017;8(1):196.

140. Medress Z, Hayden Gephart M. Molecular and genetic predictors of breastto-brain metastasis: review and case presentation. Cureus. 2015;7(1):e246.

141. Allenson K, Castillo J, San Lucas FA, et al. High prevalence of mutant KRAS in circulating exosome-derived DNA from early stage pancreatic cancer patients. Ann Oncol. 2017;28:741-7.

142. Chiou NT, Ansel KM. Improved exosome isolation by sucrose gradient fractionation of ultracentrifuged crude exosome pellets. Protocol Exchange. 2016; https://doi.org/10.1038/protex.2016.057.

143. Livshits MA, Khomyakova E, Evtushenko EG, et al. Isolation of exosomes by differential centrifugation: theoretical analysis of a commonly used protocol. Sci Rep. 2015;5:17319.

144. Helwa I, Cai J, Drewry MD, et al. A comparative study of serum exosome isolation using differential ultracentrifugation and three commercial reagents. PLoS One. 2017;12(1):e0170628.

145. Yang S, Che SP, Kurywchak P, et al. Detection of mutant KRAS and TP53 DNA in circulating Exosomes from healthy individuals and patients with pancreatic cancer. Cancer Biol Ther. 2017;0

146. Krug AK, Enderle D, Karlovich C, et al. Improved EGFR mutation detection using combined exosomal RNA and circulating tumor DNA in NSCLC patient plasma. Ann Oncol. 2017;

147. He M, Crow J, Roth M, et al. Integrated immunoisolation and protein analysis of circulating exosomes using microfluidic technology. Lab Chip. 2014;14:3773-80.

148. Supplement C. Abstracts from the fourth international meeting of ISEV. ISEV2015, Washington, D.C., USA, 2015.

149. Vykoukal J, Sun N, Aguilar-Bonavides C, et al. Plasma-derived extracellular vesicle proteins as a source of biomarkers for lung adenocarcinoma. Oncotarget. 2017;8(56):95466-80

150. Uotani K, Fujiwara T, Yoshida A, et al. Circulating MicroRNA-92b-3p as a novel biomarker for monitoring of synovial sarcoma. Sci Rep. 2017;7(1): 14634.

151. Schwarzenbach H, Hoon DS, Pantel K. Cell-free nucleic acids as biomarkers in cancer patients. Nat Rev Cancer. 2011;11:426-37.

152. Pantel K. Blood-based analysis of circulating cell-free DNA and tumor cells for early cancer detection. PLoS Med. 2016;13(12):e1002205.

153. Ashida A, Uhara $H$, Mikoshiba A, et al. Melanoma with BRAF mutation in circulating cell-free DNA despite no mutation in the primary lesion: a case report. Acta Derm Venereol. 2016;96(1):128-9.

154. Larrea E, Sole C, Manterola L, et al. New concepts in cancer biomarkers: circulating miRNAs in liquid biopsies. Int J Mol Sci. 2016;17(5)

155. Larue L, Bellacosa A. Epithelial-mesenchymal transition in development and cancer: role of phosphatidylinositol 3' kinase/AKT pathways. Oncogene. 2005;24(50):7443-54

156. Sarangi S, Mosulpuria K, Higgins MJ, Bardia A. The evolving role of circulating tumor cells in the personalized Management of Breast Cancer: from enumeration to molecular characterization. Curr Breast Cancer Rep. 2014;6(3):146-53.

157. Kato $S$, Lippman SM, Flaherty KT, Kurzrock $R$. The conundrum of genetic "drivers" in benign conditions. J Natl Cancer Inst. 2016;108(8) 
158. Norton SE, Luna KK, Lechner JM, et al. A new blood collection device minimizes cellular DNA release during sample storage and shipping when compared to a standard device. J Clin Lab Anal. 2013;27:305-11.

159. Andersen RF, Spindler KG, Jakobsen A, et al. Plasma is superior to serum for CfDNA mutation detection and monitoring. Eur J Cancer. 2012;48:148-9.

160. Al-Soud WA, Radstrom P. Purification and characterization of PCR-inhibitory components in blood cells. J Clin Microbiol. 2001;39:485-93. https://doi.org/ 10.1128/JCM.39.2.485-493.2001.

161. Fleischhacker M, Schmidt B. Circulating nucleic acids (CNAs) and cancer-a survey. Biochim Biophys Acta. 2007;1775:181-232.

162. Zhang Y, Xu Y, Zhong W, et al. Total DNA input is a crucial determinant of the sensitivity of plasma cell-free DNA EGFR mutation detection using droplet digital PCR. Oncotarget. 2017;8(4):5861-73.

163. Sherwood JL, Corcoran C, Brown H, et al. Optimised pre-analytical methods improve KRAS mutation detection in circulating tumour DNA (ctDNA) from patients with non-small cell lung cancer (NSCLC). PLoS One. 2016;11(2): e0150197.

164. Douillard JY, Ostoros G, Cobo M, et al. Gefitinib treatment in EGFR mutated caucasian NSCLC: circulating-free tumor DNA as a surrogate for determination of EGFR status. J Thorac Oncol. 2014;9:1345-53.

165. Taverna S, Giallombardo M, Gil-Bazo I, et al. Exosomes isolation and characterization in serum is feasible in non-small cell lung cancer patients: critical analysis of evidence and potential role in clinical practice. Oncotarget. 2016;7(19):28748-60.

\section{Submit your next manuscript to BioMed Central} and we will help you at every step:

- We accept pre-submission inquiries

- Our selector tool helps you to find the most relevant journal

- We provide round the clock customer support

- Convenient online submission

- Thorough peer review

- Inclusion in PubMed and all major indexing services

- Maximum visibility for your research

Submit your manuscript at www.biomedcentral.com/submit 